\title{
Solidworks based Modeling and Motion Simulation for Feed Mechanism for Ejector Pin
}

\author{
Xianying ZHENG \\ Department of Mechanical Engineering , Dalian Vocational Technology college, Dalian, 116033,
China
}

email: zxy_acc@163.com, corresponding author

Keywords: Ejector Pin, Automatic Production, Feed Mechanism, Motion Simulation

\begin{abstract}
To quickly design automatic feed mechanism for ejector pin, the Solidworks Motion functional module of Solidworks platform is utilized to establish a motion simulation model of this mechanism, whose motion and the influencing conditions are described in a visual and intuitionistic way, and the major design parameters are emphatically analyzed; this significantly simplifies the workload of motion and power analysis, shortens design cycle, cuts design cost and improves work efficiency, thereby laying a foundation for trial-manufacturing of actual prototype.
\end{abstract}

\section{Introduction}

Ejector pin is a universal die stamping and unloading member, with typical structure as shown in figure 1. Its main function is to eject the shaped part from cavity of die to disengage it from die. The ejector pins have a great many specifications. In the past, the ejector pin is mainly processed by artificial feeding and blanking, which is inefficient and has large labor intensity, while automatic feed mechanism can economize manpower and resources. The paper begins by introducing an automatic feed mechanism for ejector pin, including its structure and operating principle, followed by an analysis on the major design parameters of the mechanism. In an effort to shorten design cycle and cut design cost, the functional module Solidworks Motion[1] of Solidworks platform is adopted to establish a motion simulation model of this mechanism by dint of example, whose motion and influencing factors are described in a visual and intuitionistic way, so as to rapidly design this mechanism.

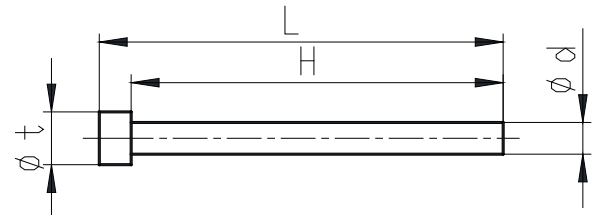

Figure 1 Structure diagram of ejector pin

\section{Composition and Operating Principle of Automatic Feed Mechanism}

Figure 2 and figurer 3 show a simple and practical feed mechanism for ejector pin, which is mainly composed of stand, side baffle of feed bin, fixed toothed plate and push-up toothed plate, etc. To use it, the operator shall firstly arrange the big ends of a bundle of ejector pins to the same side (right side in figure 2), and neatly stack up them in the placement area of ejector pins (left side in figure 3). At the bottom of feed bin have several fixed toothed plates distributed evenly by the overall length of ejector pin to support the weight of all ejector pins. Several push-up toothed plates evenly distributed on the bottom have tooth form identical to that of fixed toothed plates, which can enable up-down periodic motion. Each push-up motion moves one ejector pin toward oblique upward direction along the fixed toothed plate by a length of distance (as shown in figure 4 and figure 5). Continuous push-up motions can move the bottom ejector pin toward oblique upward direction in an array in turn, thereby enabling automatic feeding. 


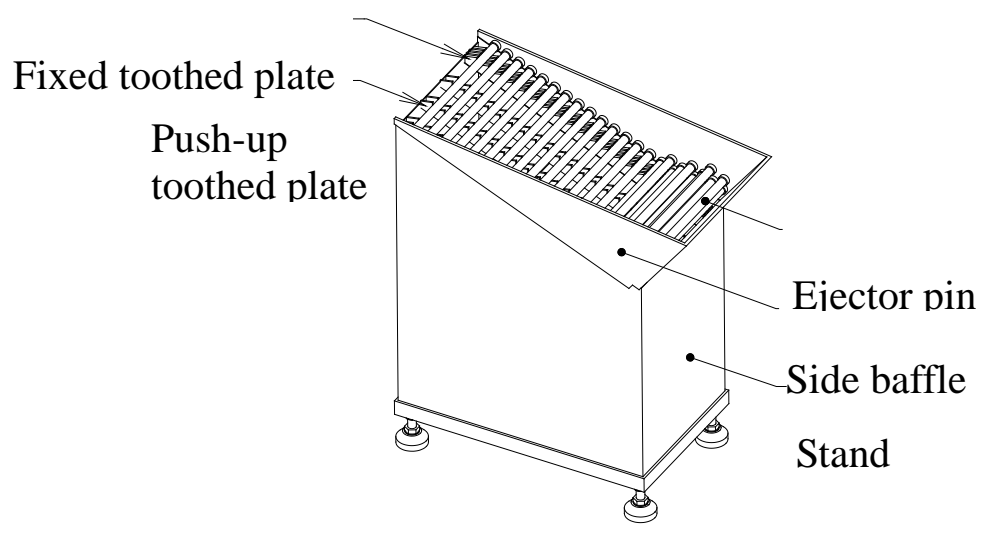

Figure 2 Contour of feed mechanism

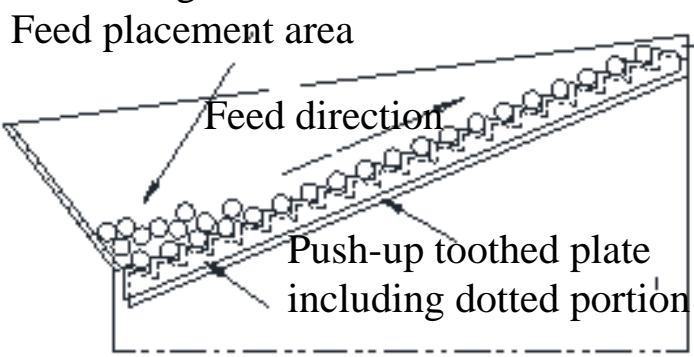

Figure 3 Schematic diagram of feed mechanism

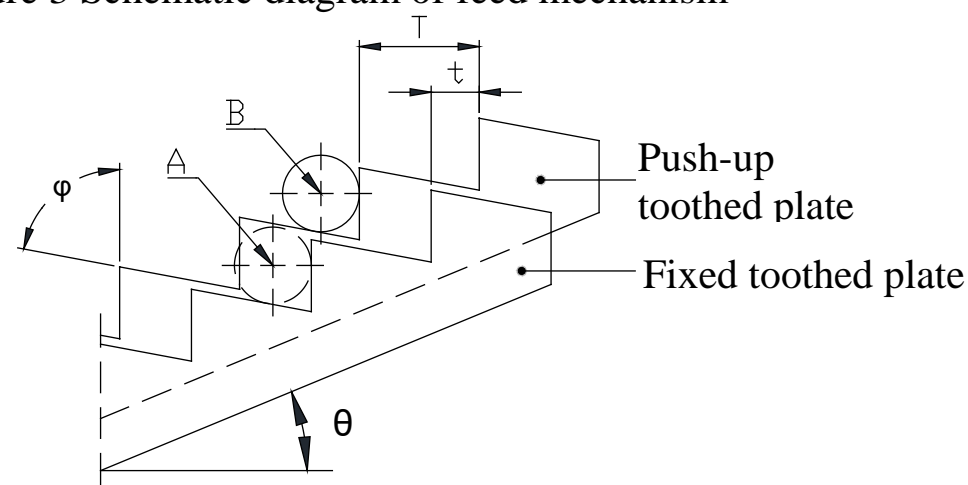

Figure 4 Push-up toothed plate pushes to the peak

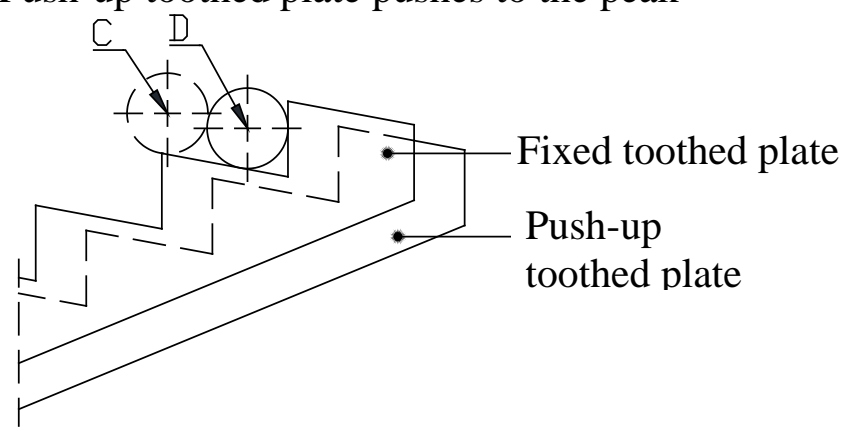

Figure 5 Push-up toothed plate descends to the nadir

\section{Major Design Parameters of Automatic Feed Mechanism}

It is observed from figure 4 that in the process of push-up toothed plate pushing from the nadir to the peak, one ejector pin moves from position A to position B; while figure 5 shows that in the process of push-up toothed plate continuing to descend from the peak to the nadir, this ejector pin rolls from position $\mathrm{C}$ to position $\mathrm{D}$. Thus in one motion cycle of push-up toothed plate, this ejector pin moves by a pitch $\mathrm{T}$ along horizontal direction. If the ejector pin's diameter is $\mathrm{d}$, the splines of the two kinds of toothed plates are staggered by a distance of $t$, then this condition should be met[2]: $0.5 \mathrm{~d}<\mathrm{T}-\mathrm{t}<1.5 \mathrm{~d}$, i.e. the space created by one pushing can and only can accommodate next ejector 
pin. Premised on meeting above conditions, the value of T-t can be set larger to improve reliability of feeding. Continue to observe figure 4, and it can be found that staggered pitch 6 should meet: $\mathrm{t}>0.5 \mathrm{~d}$.

To prevent the ejector pin from rushing forward in the process of feeding, reasonably selecting of feeding lift angle $\theta$ is also very important. The situation becomes complex due to combined influence of ejector pin size, material, feed rate of toothed plate, etc. Based on practice, usually the life angle of feed $\theta$ is set as $15^{\circ} \sim 20^{\circ}$. Continue to observe figure 4 and figure 5 , the profile angle $\varphi$ should be set as a complement angle to guarantee ejector pin rolls from position $\mathrm{C}$ to position $\mathrm{D}$ by dint of deadweight in the descending process of toothed plate. Based on practice, we usually set profile angle $\varphi$ as $75^{\circ} \sim 80^{\circ}$.

\section{Motion Simulation of Feed Mechanism}

So-called motion simulation refers to using computer to simulate kinematic state and dynamic state of mechanism. The design methods and means of engineering technicians become increasingly various in company with instant development of CAD technology and endless perfecting of functions. In especial, the extensive use and popularization of 3d CAD/CAM software makes 3D design widely applied in modern machinery product design. Solidworks is 3 dimensional entity design software based on Windows environment, with plug-in Solidworks Motion being a virtual motion simulation tool for prototype and characterized by visual, intuitionistic, simple and practical advantages. Able to help the designers to judge whether the design can achieve intended effect in early period of design, it powerfully underpins rapid design of feed mechanism for ejector pin in technology[3].

In the following, the paper will use Solidworks to structure a solid model of feed mechanism for ejector pin via example and then simulate, with analysis result able to supervise modifying structure design of parts or adjusting material of parts[4]. The physical dimension of ejector pin and the preliminarily defined design parameters of the mechanism are as shown in table 1 and table 2 .

Table 1. Physical dimension and material of ejector pin

\begin{tabular}{ccccc}
\hline $\begin{array}{c}\text { Diameter at big end } \\
\text { of ejector pin } \\
\varphi \mathrm{t} / \mathrm{mm}\end{array}$ & $\begin{array}{c}\text { Diameter of stem of } \\
\text { ejector pin } \\
\varphi \mathrm{d} / \mathrm{mm}\end{array}$ & $\begin{array}{c}\text { Total length of } \\
\text { ejector pin } \\
\mathrm{L} / \mathrm{mm}\end{array}$ & $\begin{array}{c}\text { Stem length of } \\
\text { ejector pin } \\
\mathrm{H} / \mathrm{mm}\end{array}$ & $\begin{array}{c}\text { Ejector pin } \\
\text { material }\end{array}$ \\
\hline 20 & 16 & 308 & 300 & $45 \#$ carbon steel \\
\hline
\end{tabular}

Table 2 Design parameters and feed mechanism and member material

\begin{tabular}{ccccc}
\hline Pitch & $\begin{array}{c}\text { Staggered pitch } \\
\mathrm{t} / \mathrm{mm}\end{array}$ & $\begin{array}{c}\text { Lift angle of feeding } \\
\theta /\left(^{\circ}\right)\end{array}$ & $\begin{array}{c}\text { Profile angle } \\
\varphi /\left(^{\circ}\right)\end{array}$ & Member material \\
\hline 20 & 16 & 20 & 80 & $45 \#$ carbon steel \\
\hline
\end{tabular}

Open Solidworks for modeling of parts and assembly according to parameters in table 1 and table 2. The final assembly model is as shown in figure 6 . In the modeling process, the member needs to be simplified by firstly canceling the unnecessary members (such as stand), then compressing some fine characteristics (such as chamfer, attachment hole, etc.) of used members, and finally integrating all the stationary members in the assembly into a separate part (to reduce related connection characteristics and conjugation). Above treatment conduces to improve calculation efficiency of software without a large effect on the calculation result. No conjugation relation is needed to set for ejector pins, and just manually arrange them on the bottom of feed bin. No interference phenomenon among ejector pins and between the ejector pins and other members is allowed. 


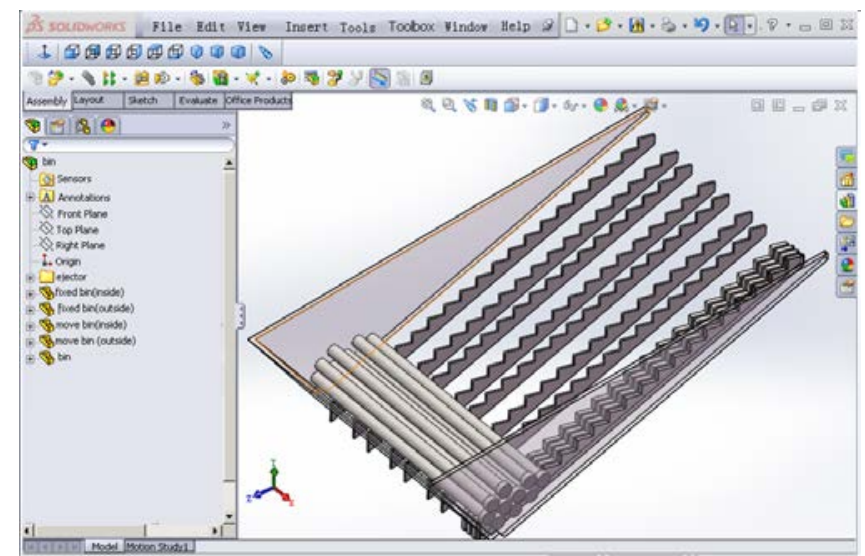

Figure 6 Modeling of assembly

\section{Following is further Motion Simulation of above Models using Solidworks Motion}

(1) Open Solidworks, guarantee the plug-in Solidworks Motion is checked.

(2) Open the model of assembly as described in figure 6.

(3) Click the tab control "MotionManager" at bottom left corner of the window to switch to the page of MotionManager.

(4) Set the type of MotionManager as "Motion analysis".

(5) As shown in figure 7, a linear motor is generated: select a vertical edge of push-up toothed plate as motion direction of linear motor, set "Motion function" as "Oscillation", set "Displacement" as "20mm", set "Frequency" as "1Hz", set "Phase difference" as "0 degree".

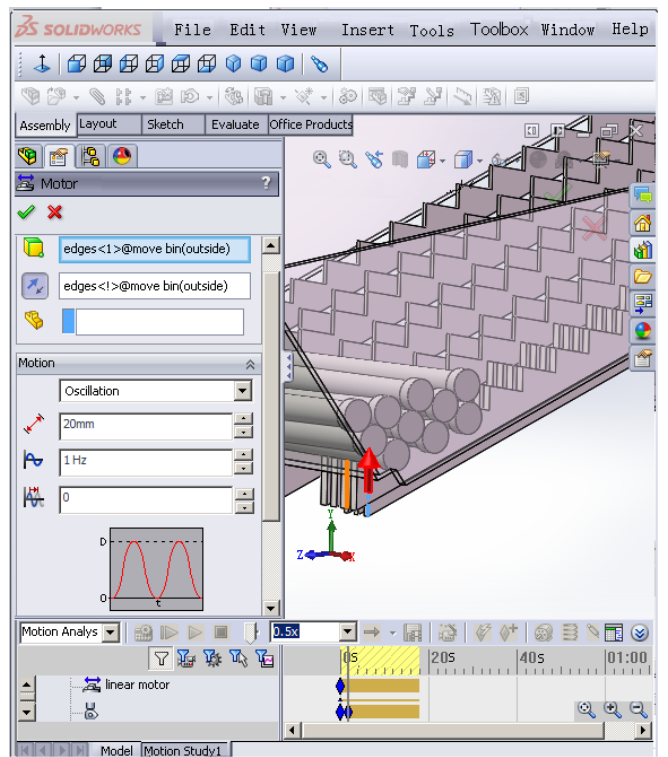

Figure 7 Define linear motor

(6) Set the direction of gravitational vector as vertically downward, and value as "9.8m/s2"

(7)Define contact performance between members: Click the "Contact" button in MotionManager toolbar, check all members in the column of "Select contact face", and check the tap control of "Material", select "Steel (Dry)" in the column of "Material name"

(8) Click the "Operate" button in MotionManager toolbar to begin motion simulation, and save result after operation.

(9) As shown in figure 8, play back the course of motion simulation in the form of animation to observe whether this design is up to design requirements. 


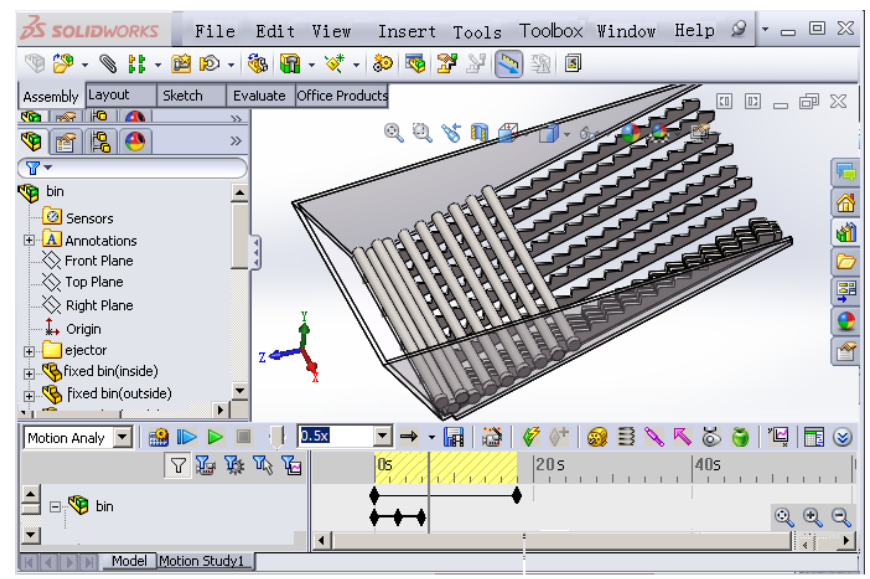

Figure 8 Animation playback of MotionManager

The observation and analysis on simulation result in this example can fully prove feasibility of the design proposal made in the early period, i.e. the mechanism designed this time can enable feeding of certain kind of ejector pins stably, reliably and efficiently (the feed quantity in unit time is $1 / \mathrm{s}$ ). If simulation result is less than ideal, we can adjust some influencing factors (such as major design parameters, physical dimension of member, or member material, etc.) for one or more analyses of motion simulation until the result is satisfying. Compared with traditional design method, the motion simulation design herein can shorten the original design verification cycle of several months to a few days, a significant improvement on design efficiency.

\section{Conclusion}

The paper preliminarily delves into the modeling and motion simulation of feed mechanism for ejector pin based on Solidworks platform, and illuminates the superiority of this design method via example. Currently, this design method has been applied to automatic production. The practice proves it is visual and intuitionistic, simple and practical, with product development cycle significantly shortened, product design and manufacturing cost reduced, thereby delivering satisfactory economic benefit.

\section{References}

[1] Chaoxiang Chen. Tutorial for Motion Simulation of SolidWorks [M]. Beijing: China Machine Press, 2012

[2] Zongyan Wang, et al. The Advanced Development Technique for Machinery Products Using SolidWorks [M].Beijing: Press of Beijing Institute of Technology, 2005

[3] Chaoxiang Chen. Concise Edition of Advanced Course for SolidWorks [M]. Beijing: China Machine Press, 2010

[4] Guofu Yin. Detailed Description of Redevelopment Cases of SolidWorks [M]. Beijing: China Machine Press, 2006 